\title{
ENVIRONMENT CONSCIOUS, BIOMORPHIC CERAMICS FROM PINE AND JELUTONG WOOD PRECURSORS
}

M. Singh

QSS Group, Inc.

MS106-5, Ceramics Branch

NASA Glenn Research Center

Cleveland, $\mathrm{OH} 44135$

\author{
Bo-Moon Yee \\ Box J173 \\ Lehigh University \\ 39 University Drive \\ Bethlehem, PA 18015
}

\begin{abstract}
Environment conscious, biomorphic ceramics have been fabricated from pine and jelutong wood precursors. A carbonaceous preform is produced through wood pyrolysis and subsequent infiltration with oxides $\left(\mathrm{ZrO}_{2}\right.$ sols $)$ and liquid silicon to form ceramics. These biomorphic ceramics show a wide variety of microstructures, densities, and hardness behavior that are determined by the type of wood and infiltrants selected.
\end{abstract}

\section{INTRODUCTION}

In recent years, there has been great interest in using biomimetic-based processing approaches to fabricate a variety of oxide and non-oxide based structural and functional materials. Wood has been considered as a precursor material to fabricate biomorphic ceramics. Possible applications of these materials include filters and catalyst support, automotive components, tooling and wear components, armor, and light weight cellular ceramics. A carbon template is produced from the pyrolysis of wood, which is further infiltrated with oxides and/or non-oxides to form ceramics [1-12]. These biomorphic ceramics have several benefits over traditional ceramics. A wide variety of microstructures can be obtained, based on the type of wood selected. The use of wood and this process provides a low-cost starting material and near-net and complex shape capabilities, instead of the simple shapes normally produced by traditional ceramic processing techniques.

With the many benefits of using wood as a precursor material, it is critical to have a greater understanding of its structure. Wood is classified as a composite material that behaves anisotropically with a cell morphology that varies with each species [13-14]. Anisotropy in wood is the result of the orientation and alignment 
of cells and cell walls, as well as variation in density. Wood is composed of cellulose, hemicellulose, and lignin, which decompose to produce char in the form of amorphous carbon during pyrolysis and produces an anisotropic cellular structure. The overall pyrolysis process of wood has been investigated by a number of investigators and has been summarized in a review publication [15].

In this work, two types of wood (jelutong and pine) were investigated. Eastern White Pine (Pinus strobes), a softwood, is typically used as a structural element [13] in construction. Jelutong (Dyera costulata) is an imported hardwood from Malaysia that is used mainly to produce latex for chewing gum. With a low density and easy workability, jelutong is ideal for infiltration of oxide sols and molten silicon into a complex-shaped component. In this paper, wood pyrolysis, infiltration behavior, and microstructures of biomorphic ceramics made from jelutong and pine will be presented.

\section{EXPERIMENTAL PROCEDURES}

One block of jelutong and three blocks of pine were dried in an oven at $100^{\circ} \mathrm{C}$ and pyrolyzed in an argon atmosphere in a Thermcraft ${ }^{\top M}$ tube furnace up to $1000^{\circ} \mathrm{C}$. Pyrolysis is the decomposition of a wood specimen during heating in an inert atmosphere to release volatiles, leaving behind a carbonaceous preform with cell-like structures. The jelutong blocks measured $15 \mathrm{~cm} \times 4.5 \mathrm{~cm} \times 4.5 \mathrm{~cm}$, while the dimensions of the pine blocks were $14 \mathrm{~cm} \times 3.5 \mathrm{~cm} \times 3 \mathrm{~cm}$. Afterwards, the blocks were cut into approximately $0.4 \mathrm{~cm}$ thick slices that were to be infiltrated.

Some carbonaceous performs were infiltrated with silicon at $1460^{\circ} \mathrm{C}$ for one hour in a Centorr ${ }^{\mathrm{TM}}$ vacuum furnace. Both carbon performs and silicon carbide samples were infiltrated with $\mathrm{ZrO}_{2}$ sol in a Buehler ${ }^{\mathrm{TM}}$ vacuum impregnation chamber. After infiltration, the samples were dried in a furnace and then placed in a tube furnace for calcinations up to $400^{\circ} \mathrm{C}$. This process was repeated up to five times. To understand the progress of the infiltration, some samples were infiltrated only one or three times. The calcined samples were fired at $1100^{\circ} \mathrm{C}$ in air for conversion of the infiltrant to $\mathrm{ZrO}_{2}$.

The original pore structures of the two types of wood were analyzed by viewing fresh fracture surfaces of jelutong and pine using a scanning electron microscope (SEM). Images were taken of two orientations of the carbon structures: perpendicular and parallel to the growth direction of the tree. The growth direction is equivalent to the longitudinal axis of the trunk. The SEM was also used for the analysis of the carbon preforms infiltrated with $\mathrm{ZrO}_{2}$ and the porous $\mathrm{SiC}$ infiltrated with $\mathrm{ZrO}_{2}$ (one, three, and five times). $\mathrm{Si}$ and $\mathrm{SiC}$ were not readily distinguishable in the SEM images; therefore the samples infiltrated with only Si were viewed with a light optical microscope (LOM). The LOM was also used to characterize the porous $\mathrm{SiC}$ samples infiltrated with $\mathrm{ZrO}_{2}$. 
The microhardness tests were performed using a Knoop indenter with a $500 \mathrm{~g}$ load to measure the hardness in different regions: reaction formed $\mathrm{SiC}, \mathrm{Si}$, and the interface of $\mathrm{SiC}$ and $\mathrm{Si}$. A total of six samples were tested: pine (perpendicular to the growth direction), jelutong (perpendicular and parallel to the growth direction), and three porous $\mathrm{SiC}$ ceramics from jelutong, that were infiltrated with $\mathrm{ZrO}_{2}$ (one, three, and five times). Five indentations were made in each region and the average Knoop hardness value for each region in each sample was calculated.

\section{RESULTS AND DISCUSSION}

\section{Pyrolysis and Microstructure}

After the pyrolysis, the wood pieces retained their shape, but decreased in size. The pyrolysis shrinkage in jelutong was $\sim 25 \%$ in dimensions and the total volume decreased by $\sim 60 \%$. The dimensions of the pine pieces decreased by roughly $\sim 22 \%$, while the total volume was reduced by $50 \%$. Cracks appeared in the pine blocks due to shrinkage stress created from the exterior of the blocks decomposing at a faster rate than the middle, but did not appear in the jelutong block. The heating rates are crucial to the integrity of the pyrolyzed blocks, and each type of wood requires different rates, which are dependent on their density.

The microstructures of the pyrolyzed woods are shown in Figs. 1 and 2, where the white outlines are carbon and the black areas are the pores. The microstructure of the pine in the plane perpendicular to the growth axis (Fig. 1a) shows fairly uniform pore structure. The amount of ray cells in pine is less than in jelutong (Fig. 1b), indicating that the strength of pine would be higher than jelutong in the direction that is perpendicular to the growth. Fig. 2a shows that the pyrolyzed jelutong has a non-uniform pore structure, with sets of large pores surrounded by smaller pores of varying size. The ray cells in jelutong are evident in Fig. 2b, which shows the view that is parallel to the direction of tree growth.

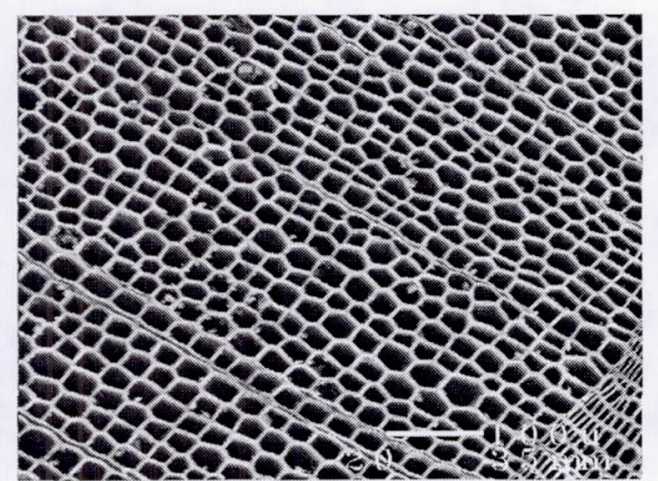

a

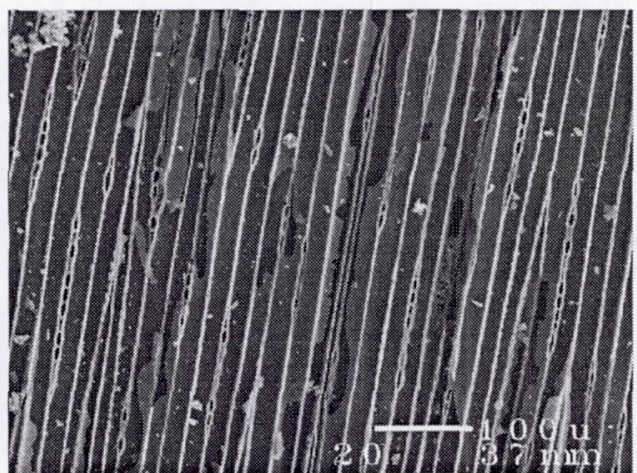

b

Fig. 1: SEM micrographs of pine (a) perpendicular to the growth direction; and (b) parallel to the growth direction (200X). 


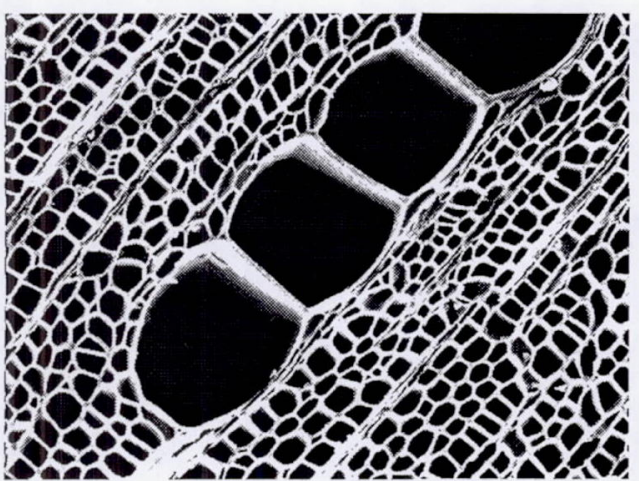

a

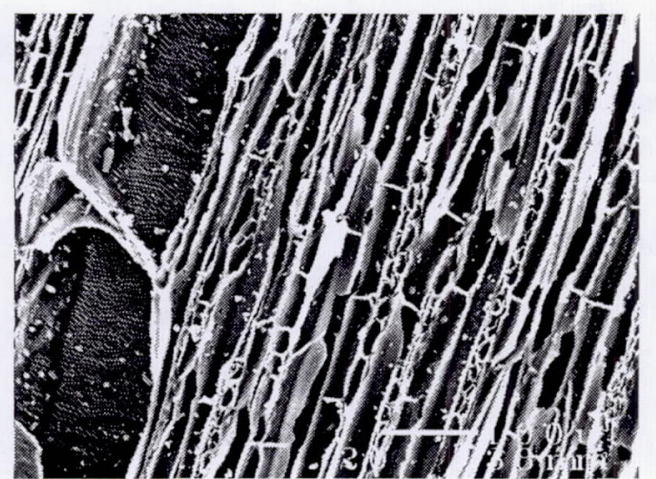

b

Fig. 2: SEM micrographs of jelutong (a) perpendicular to the growth direction; and (b) parallel to the growth direction (200X).

When the carbon preforms were infiltrated with silicon, the silicon reacted with the carbon to form silicon carbide (SiC). In Fig. 3 a and b, the dark gray outlines represent the $\mathrm{SiC}$, while the light gray areas are excess silicon. The reacted $\mathrm{SiC}$ retained the original structure of the wood. Through further treatment, the excess silicon can be removed, leaving behind a porous $\mathrm{SiC}$ structure.

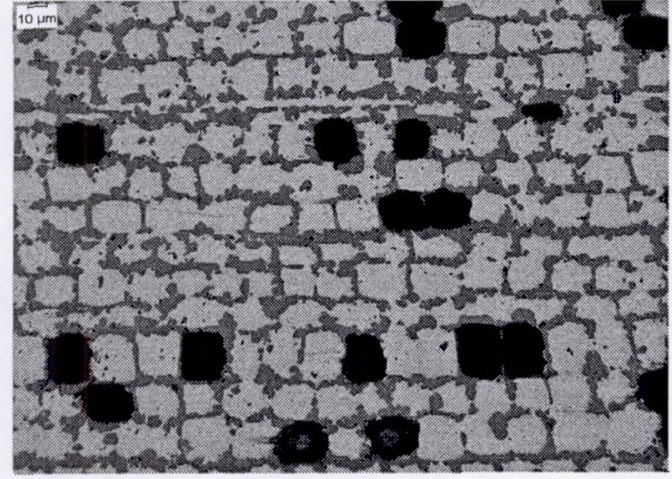

a

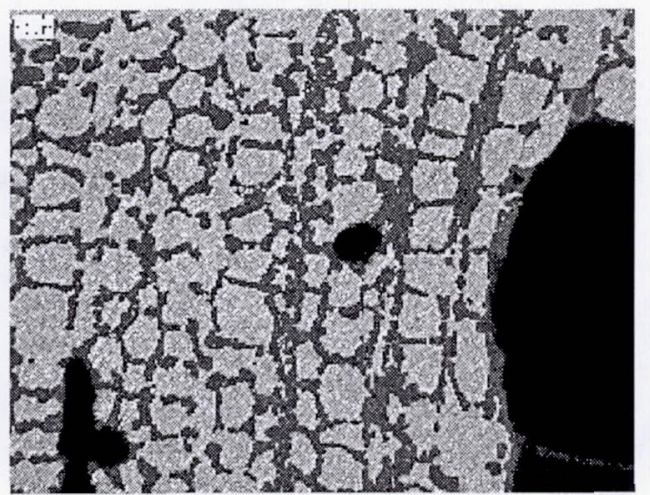

b

Fig. 3: (a) Micrograph of silicon infiltrated pine and (b) silicon infiltrated jelutong (200 X, gray: silicon carbide; white: silicon and black: porosity).

Infiltration of sols in $\mathrm{C}$ and $\mathrm{SiC}$

Pine and jelutong samples infiltrated with $\mathrm{ZrO}_{2}$ (three and five times) are shown in Figs. 4-a and 4-b, respectively. The original structure of jelutong can still be seen, but $\mathrm{ZrO}_{2}$ now coats it and the pores are filled with crystallized $\mathrm{ZrO}_{2}$. As the number of infiltrations increased, the amount of oxide deposited increased, with $\mathrm{ZrO}_{2}$ eventually completely filling the pores. The same trend was observed in 
the pine samples infiltrated with $\mathrm{ZrO}_{2}$ three and five times. As with three infiltrations in jelutong, the original structure of pine can still be seen, but after five infiltrations, cracks formed in the structure.

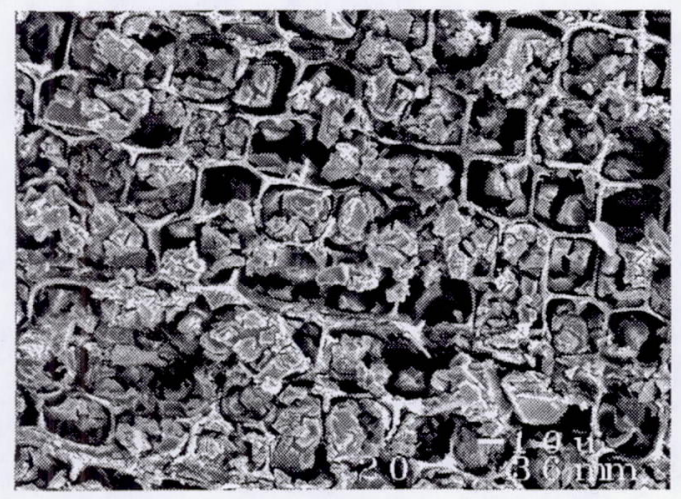

a

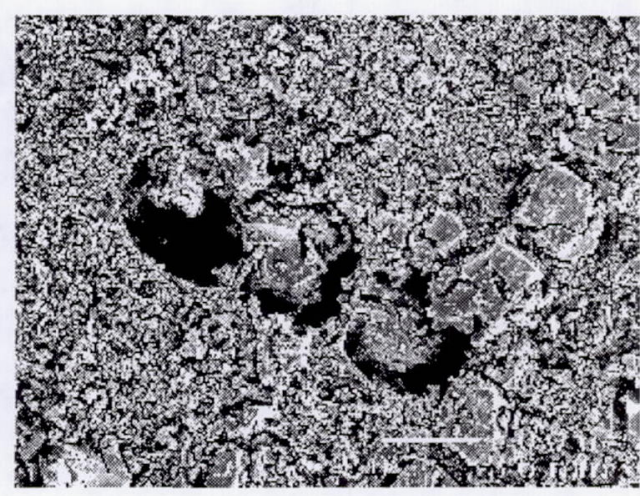

b

Fig. 4. Photomicrograph (perpendicular to the growth direction) of carbon preforms infiltrated three times with $\mathrm{ZrO}_{2}$ sol (a) pine, 500X; (b) jelutong, 200X.

Prior to the carbon samples being infiltrated, the preforms had similar densities (around $0.3 \mathrm{~g} / \mathrm{cm}^{3}$ ), but after the third infiltration, the amount of mass gain of pine leveled off while jelutong continued to accumulate mass. The large sets of pores in the jelutong structure provided additional areas for the $\mathrm{ZrO}_{2}$ infiltration even after the smaller pores were filled. Fig. 5 is a plot of the densities of jelutong and pine after each infiltration.

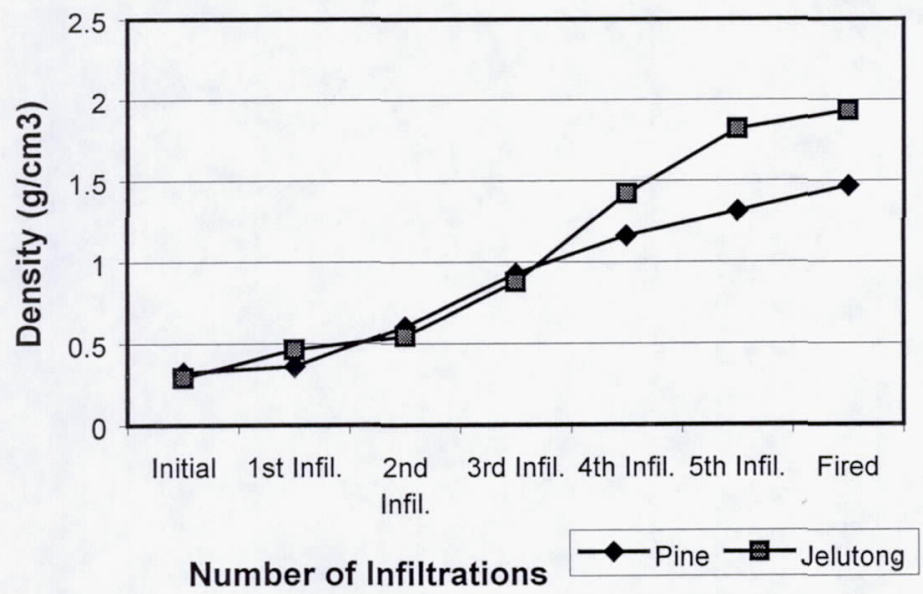

Fig. 5: Density of porous performs of pine and jelutong after various infiltration and pyrolysis cycles. 
Porous $\mathrm{SiC}$ samples from jelutong and pine were also infiltrated with $\mathrm{ZrO}_{2}$ (one, three, and five times). After the silicon infiltration, the large pores were not completely filled, so the oxide mostly deposited in the large pores, as well as coating the $\mathrm{SiC}$ structure. As the number of these infiltrations increased, the amount of $\mathrm{ZrO}_{2}$ in the large pores increased. Details of these results will be discussed in another publication [16].

\section{Microhardness}

The average values from the microhardness tests are plotted in Fig. 6. The average Knoop hardness values for the $\mathrm{ZrO}_{2}$-infiltrated $\mathrm{SiC}$ decreased from 1490.6 $\mathrm{Hk}$ to $1403.8 \mathrm{Hk}$ as the number of oxide infiltrations increased, as expected due to the softer oxide coating. The lowest hardness value for $\mathrm{SiC}$ in the jelutong sample tested parallel to the growth direction is believed to be attributable to the orientation of the fibers. Wood is an anisotropic material whose properties are dependent upon the direction of the loading, leading to a preferred orientation of the porous structure.

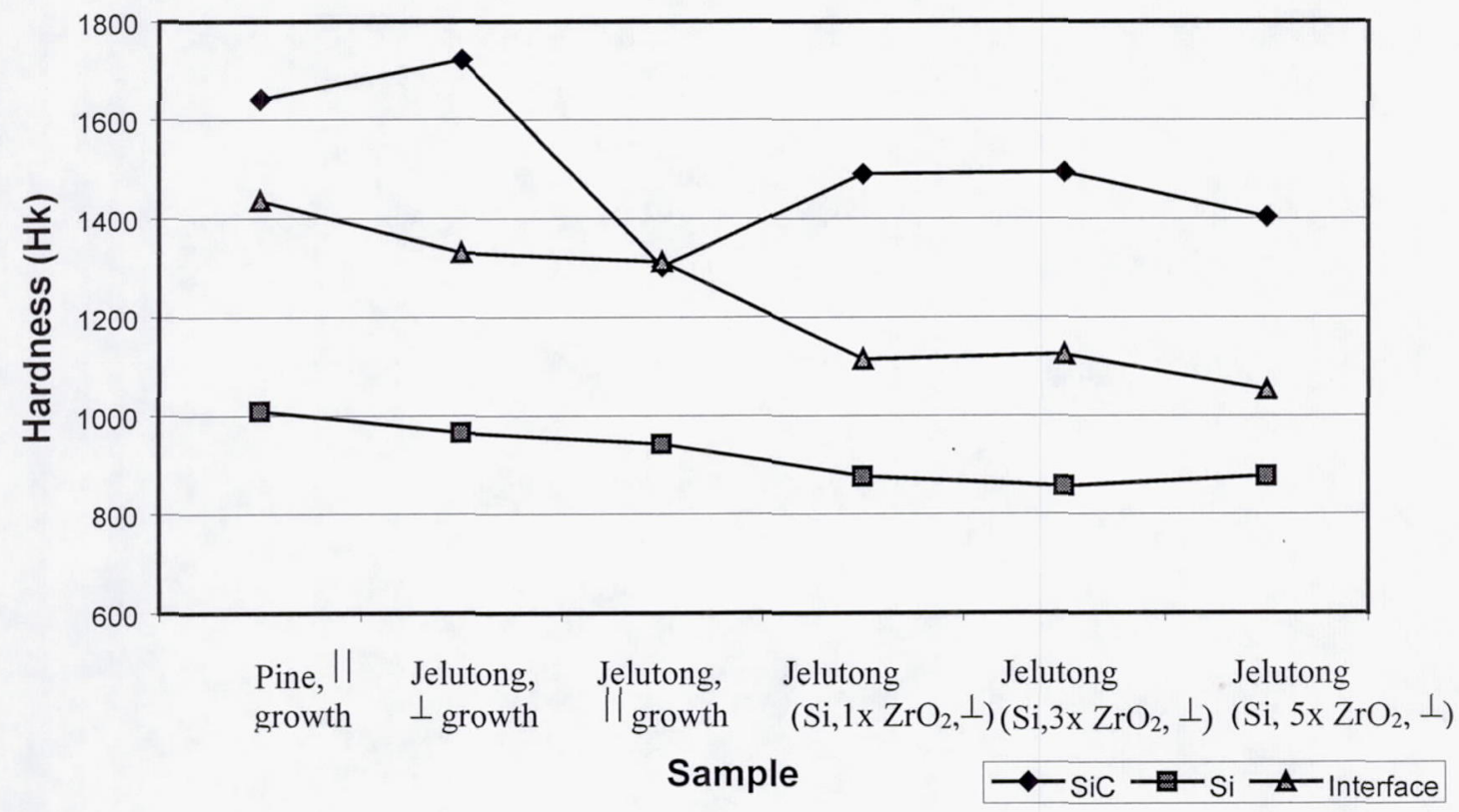

Fig. 6: Microhardness of various phases in pine and jelutong specimens after silicon and oxide infiltration.

The total average Knoop hardness value of all $\mathrm{SiC}$ areas was $1509.0 \mathrm{Hk}$, which is significantly lower than the documented value of $2480 \mathrm{Hk}$, but even this value varies depending on the processing technique used [17]. 


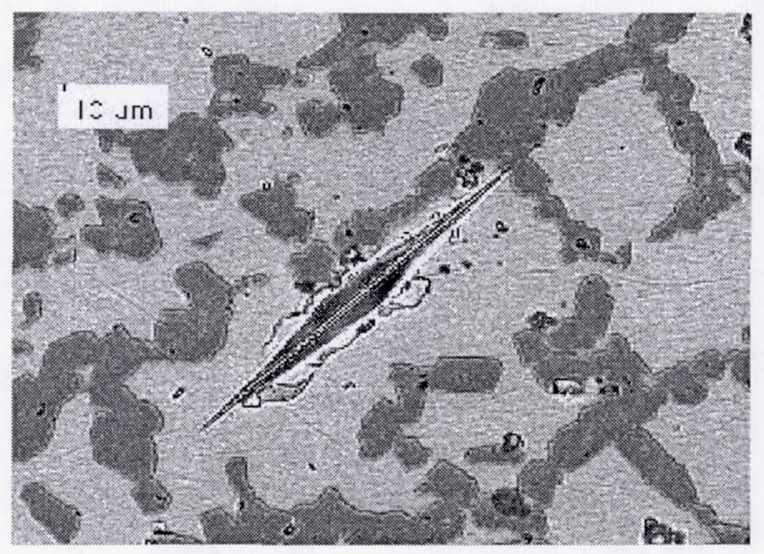

Fig. 7: Photomicrograph of Knoop hardness test performed on porous SiC from jelutong after five $\mathrm{ZrO}_{2}$ infiltrations (500x).

Indentations in pure $\mathrm{SiC}$ were hard to perform due to the size of the $\mathrm{SiC}$ areas relative to the size of the indenter; therefore, accurate hardness values were difficult to obtain. Fig. 7 is a photomicrograph of an indentation in the interface of $\mathrm{SiC}$ and $\mathrm{Si}$ and shows the size of the $\mathrm{SiC}$ areas compared to the indenter. The areas filled with excess $\mathrm{Si}$ were larger in size, making indentations in pure $\mathrm{Si}$ easier to make. The total average Knoop hardness value for $\mathrm{Si}$ was $921.3 \mathrm{Hk}$, which is closer in range to the recorded hardness values of 950-1150 Hk [18]. At the interface of $\mathrm{SiC}$ and $\mathrm{Si}$, the total average Knoop hardness value fell in between the values of $\mathrm{SiC}$ and $\mathrm{Si}$, as expected, at $1228.3 \mathrm{Hk}$.

\section{CONCLUSIONS}

Ecoceramics (biomorphic ceramics derived from natural precursors) provide opportunities for expanded designs and applications. Starting with natural wood, the desired final shape of the component can be obtained in a wood preform, and is retained throughout the process. The microstructure of the original biological structure is also maintained throughout the procedure, and allows knowledge of the resulting properties of the product. Finally, the starting materials used are inexpensive and are a renewable resource.

\section{ACKNOWLEDGEMENTS}

The author would like to thank Richard Dacek, John Setlock, and Myles McQuater for their technical assistance. The technical review and comments on the manuscript by Mr. James D. Kiser of NASA Glenn Research Center and Dr. David Lewis III of Naval Research Laboratory, Washington, DC are also acknowledged. 


\section{REFERENCES}

1. J.E. Mark and P.D. Calvert, "Biomimetic, hybrid and in-situ composites", Mater. Sci. and Engg., C1, 159 (1994).

2. T. Ota, M. Takahashi, T. Hibi, M. Ozawa, and H. Suzuki, "Biomimetic process for producing SiC wood”, J. Am. Ceram. Soc., 78, 3409 (1995).

3. P. Greil, T. Lifka, and A. Kaindl, "Biomorphic silicon carbide ceramics from wood: I and II", J. Eur. Ceram. Soc., 18, 1961 (1998).

4. P. Griel, "Biomorphic ceramics from lignocellulosics", J. Eur. Ceram. Soc., 21 (2001) 105-118.

5. H. Sieber, C. Hoffmann, A. Kaindl, P. Greil. Biomorphic Cellular Ceramics. Advanced Engineering Materials 2000, 2, No. 3, pp. 105-109.

6. D.-W. Shin, S.S. Park, Y.-H. Choa and K. Niihara, "Silicon/silicon carbide composites fabricated by infiltration of a silicon melt into charcoal", J. Am. Ceram. Soc., 82, 3251 (1999).

7. D.C. Nagle and C.R. Bryne, "Carbonized wood and materials formed there from", US Patent 6, 124, 028 (2000).

8. M. Singh, "Environment conscious ceramics (Ecoceramics)", Ceram. Sci. Engg. Proc., 21 [4] 39-44 (2000).

9. J. Martínez-Fernández, F.M. Valera-Feria and M. Singh, "High temperature compressive mechanical behavior of biomorphic silicon carbide ceramics", Scripta Materialia, 43 813-818 (2000).

10. G. Qiao, R. Ma, N. Cai, C. Zhang, and Z. Jin, "Mechanical properties and microstructure of $\mathrm{Si} / \mathrm{SiC}$ materials derived from native wood", Mater. Sci. Engg., A 323 (2002) 301-305.

11. M. Singh, "Environment conscious ceramics (Ecoceramics)", NASA/TM2001-210605, NASA Glenn Research Center, Cleveland, OH.

12. M. Singh, "Ecoceramics: ceramics from wood", Advanced Materials and Processes, March 2002, ASM International, Materials Park, OH.

13. "Wood Handbook- Wood as an Engineering Material", Forest Products Laboratory, USDA Forest Service, Madison, WI, General Technical Report, FPL-GTR-113 (1999).

14. "Concise Encyclopedia of Wood and Wood-Based Materials", A.P. Scniewind, Ed., Pergamon Press, NY (1989).

15. S. Sinha, A. Jhalani, M.R. Ravi, and A. Ray, "Modeling of pyrolysis in wood: a review", J. Solar Energy Society of India, 10, 1 (41-62 (2000).

16. M. Singh and Bo-Moon Yee, "Microstructure and properties of biomorphic ceramics from wood", to be submitted (2002).

17. University of Michigan, Knoop Hardness Number, KHN http://www.lib.umich.edu/dentlib/Dental tables/Knoophard.html

18. W.R. Runyan. Silicon Semiconductor Technology, McGraw-Hill Book Company, New York,(1965). 